\title{
HOW IS WORK LIFE QUALITY AS ATTORNEY? DITINJAU DARI TRANSFORMATIONAL LEADERSHIP
}

\author{
Rianda Elvinawanty \\ Novita Christi Samosir \\ Jesselyn \\ Ancelin \\ Agus Susanto \\ Fakultas Psikologi \\ Universitas Prima Indonesia \\ Jalan Sekip Simpang Sikambing Medan, Sumatera Utara
}

\begin{abstract}
The ideal leader is a person able to inspire his followers to put the goodness of the organization ahead of personal interests and give special influence to them as to improve their work life quality work lives. Thus, the intention of this study was to determine the correlation among transformative leadership and quality work of life. Subjects in this study were prosecutors at High Court of North Sumatera as many as 105 prosecutors selected with purposive sampling method. Data were altained by transformational leadership and work life quality scale then an analysis test consist of normality distribution and linearity test for colleration were conducted. Product Moment Correlation technique is used as an analysis of the results of research helped by SPSS. The analysis result revealed that the correlation coefficient was 0.625 and $p=0.000$ ( $p$ $<0.05)$. This indicates that a positive relation exists amongst transformative leadership and quality work of life. These calculation results conceal that the contribution given by transformational leadership to quality work of life is 39 percent, while the remaining 61 percent influenced by other aspects. Based on these results, the hypothesis in this study was accepted, means there is a positive correlation among transformational leadership and quality work of life.
\end{abstract}

\section{Keywords $\quad$ : Transformational leadership, Quality of work life}

\begin{abstract}
Abstrak---Pemimpin ideal merupakan pemimpin yang mampu memberi inspirasi terhadap pengikutnya agar mendahulukan kebaikan organisasi diatas kepentingan pribadi serta memberi pengaruh istimewa pada pengikutnya sehingga meningkatkan kualitas kehidupan kerja mereka. Maka dari itu, penelitian ini dilakukan untuk mengetahui kolerasi antara transformational leadership dengan quality of work life. Subjek pada penelitian ini ialah jaksa di Kejaksaan Tinggi
\end{abstract}


Sumatera Utara sebanyak 105 jaksa dipilih menggunakan metode purposive sampling.Data diambil dengan skala transformational leadership dan work life quality yang kemudian dilakukan uji analisis terdiri atas uji normalitas dan linearitas hubungan.Teknik korelasi Product Moment dipakai sebagai penganalisa hasil data penelitian dengan bantuan SPSS.Hasil analisis data memperoleh koefisien korelasi sebesar 0,625 dan nilai sig 0,000 ( $\mathrm{p}<0,05)$.Ini berarti ada korelasi positif antara transformational leadership dengan quality of work life. Hasil perhitungan memperlihatkan sumbangan yang diberikan variabel transformational leadership terhadap quality of work life sebesar 39 persen, dan selebihnya dikarenakan faktor lain sebesar 61 persen. Berdasarkan hasil penelitian disimpulkan bahwa ada korelasi positif antara transformational leadership dengan quality of work life danhipotesis penelitian diterima.

\section{Kata kunci :Transformational Leadership, Quality of Work Life}

\section{PENDAHULUAN}

Manusia merupakan makhluk sosial, karena manusia membutuhkan antar sesama untuk bertahan hidup ataupun berkembang. Setiap individu yang saling membutuhkan dalam mencapai tujuan yang sama akan membentuk suatu kelompok atau himpunan organisasi. Namun, ada kalanya sebuah organisasi menghadapi masalah yang tidak dapat diselesaikan oleh organisasi itu sendiri dan membutuhkan bantuan dari pihak lain bahkan bila dibiarkan akan bertambah rumit dan merugikan masyakrakat di sekitarnya. Unsur aparatur negara seperti pegawai negeri mengemban tugas sebagai public service (pelayan masyarakat), memiliki peran penting dalam penyelenggaraan tujuan pembangunan dan keadaan sesuai dengan muatan Undang-Undang Dasar 1945 No. 43 Tahun 1999 pasal 3 ayat 1 tentang Pokok-pokok Kepegawaian yaitu sebagai unsur aparatur Negara, pegawai negeri mengemban tugas untuk melayani masyarakat dengan professional, adil, jujur dan seimbang pada pelaksanaan tugas negara, pembangunan dan pemerintahan. Di era globalisasi, organisasi dituntut untuk mempertahankan diri dalam menghadapi masalah sumber daya manusia. Human resources berperan utama di setiap kegiatan organisasi (Thoha, 2005).

Salah satu pegawai negeri yang bertanggung jawab dalam mengambil tindakan terhadap pelanggaran tertentu kepada masyarakat secara profesional, jujurn adil, dan merata adalah jaksa 
yang bekerja di Kejaksaan Tinggi Negeri.Jaksa merupakan sebuah institusi/organisasi hukum yang didirikan oleh pemerintah untuk menjaga ketentuan hukum yang berlaku. Hukum seharusnya mengatur dan melindungi serta menciptakan keseimbangan jikalau ada pelanggaran atas ketentuan hukum tersebut demi kepentingan umumdalam arti apabila terjadi kelalaian, tindakan yang merugikan dan mengusik kesetabilan khalayak umum sesuai dengan yang telah dikehendaki dalam ketentuan hukum itu, maka pelanggarannya akan memperoleh sanksi dari masyarakat. Sanksi berupa pengambilan tindakan terhadap pelanggaran guna untuk mengembalikan keseimbangan (Djamali, 2014).

Salah satu contoh kasus yang dikarenakan kurangnya perhatian pemimpin terhadap kualitas kehidupan kerja pengikutnya terjadi di tahun 2014, dimana pemogokan kerja terjadi terhadap ratusan PNS pengadilan yang bertugas sebagai panitera.Mereka menuntut kesejahteraan layaknya hakim dinaikkan.Pemogokan ini mengakibatkan berhentinya pelaksanaan peradilan.Mereka yang tidak mampu menperoleh layanan pengadilan mencapai angka ratusan.Sekurangnya 47 pengadilan telah melakukan pemogokan di berbagai daerah yang ada di Indonesia. Tuntutan yang diajukan sama berupa pemberian atensi yang lebih pada kesejahteraan. Minimnya kesejahteraan yang dijalani oleh PNS pengadilan menjadikan rendahnya rasa aman yang ingin dimiliki mereka sehingga kinerja mereka menurun (Detik, 2014).

Survei awal yang dilakukan peneliti pada beberapa pegawai Kejaksaan Tinggi Negeri menyatakan bahwa dalam menghadapi pekerjaan masing-masing pekerjaan memiliki resiko, sedangkan resiko yang dihadapi seorang jaksa disini adanya suatu ancaman kerja dalam menghadapi perkara-perkara yang hendak diselesaikan. Beberapa jaksa mengaku adanya ancaman yang dialami mereka selama tugas. Mereka membutuhkan pengawal, sebab selama ini tidak semua aparat hukum bisa menggunakan senjata sebagai alat perlindungan diri dalam, bekerja sehingga hal tersebut mempengaruhi work life quality para jaksa.

Faktor yang mempengaruhi kualitas kehidupan kerja diantaranya ialah transformational leadership.Hal ini dibuktikan melalui penelitian sebelumnya oleh Azalea dan Himam (2014) yang menunjukan ada pengaruh positif antara kepemimpinan transformasional dan kualitas kehidupan kerja. Peningkatan aspek-aspek kepemimpinan transformasional yang digunakan seperti pemimpin yang memiliki kharisma mampu menciptakan motivasi dengan dasar komitmen 
dan jati diri secara emosional terhadap visi, filsafat juga akan meningkatkan kualitas kehidupan kerja karyawan.

Bass dan Riggio (2006) menyatakan kepemimpinan transformasional (transformational leadership) adalah kepemimpinan yang memberi dukungan pada pengikutnya untuk melakukan lebih, bahkan lebih dari apa yang mereka bayangkan, gaya kepemimpinan yang memberi tantangan yang lebih dari ekspektasi orang-orang, sehingga mungkin untuk mencapai performa terbaik, bahkan lebih dalam lagi seorang transformational leadership memperhatikan pengembangan karyawannya secara individual, bahkan melatih mereka sehingga mereka berpotensi menjadi pemimpin.

Penelitian Helmiatin (2014) terhadap responden yang terdiri dari 233 karyawan, staff administrasi di UT menunjukkan adanya hubungan positif transformasional leadership terhadap work life quality.Pemimpin yang menginspirasi para pengikutnya agar mendahulukan kebaikan organisasi diatas kepentingan pribadi dan berpengaruh luar biasa pada diri mereka ialah pemimpin yang baik, hal ini meningkatkan kualitas kehidupan kerja.

Dari fenomena di atas, peneliti tertarik untuk meneliti mengenai "quality of work life ditinjau dari transformasional leadership pada jaksa di Kejaksaan Tinggi Sumatera Utara.”

\section{METODE PENELITIAN}

\section{Partisipan}

Populasi pada penelitian ini ialah jaksa di Kejaksaan Negeri Sumatera Utara dengan karakteristik berpengalaman minimal 1 tahun dan masih aktif yaitu sebanyak 150 karyawan. Sampel penelitian yakni sebanyak 105 jaksa. Jumlah tersebut diperoleh sesuai dengan ketentuan Isaac dan Michael (1995) yaitu hasil perhitungan sampel minimal 105 orang dan presentasi kesalahan $5 \%$. 


\section{Desain}

Penelitian yang digunakan adalah penelitian kuantitatif. Menurut Sugiyono (2010) pendekatan kuantitatif adalah pendekatan yang menggunakan data yang berbentuk angka pada analisis statistik. Berdasarkan tingkat penjelasan dari kedudukan variabelnya maka penelitian ini bersifat asosiatif kausal, yaitu penelitian yang mencari hubungan atau pengaruh sebab akibat antara variabel independen (Transformational leadership) terhadap variabel dependen (Quality of work life).

\section{Prosedur}

Prosedur penelitian yang pertama ialah mempersiapkan skala yang akan digunakan saat proses penelitian, surat permohonan dilakukannya penelitian, uji coba skala untuk mengetahui validitas dan reliabilitas skala tersebut dan analisis data.

\section{1) Persiapan Administrasi}

Setelah skala selesai disusun, peneliti melakukan try out pada alat ukur dan meminta surat izin penelitian pada pihak Fakultas Psikologi Universitas Prima Indonesia, selanjutnya mengirimkan surat tersebut kepada Kepala Kejaksaan Tinggi Sumatera Utara agar dapat dilaksanakan penelitian. Setelah memberikan surat izin penelitian dan memperoleh izin dari pihak kejaksaan, peneliti segera menjadwalkan kapan dilaksanakan penelitian tersebut. Peneliti juga diberikan surat keterangan dari pihak kejaksaan yang menyatakan tentang kebenaran dan keterangan atas pelaksanaan penelitian yang dilakukan.

2) Persiapan Alat Ukur Penelitian meliputi persiapan skala work life quality dan skala transformational leadership yang disusun mengikuti pengukuran quality of work life yang diungkapkan oleh Reddy dan Reddy (2010) dan aspek transformational leadership yang dikemukakan oleh Avolio dan Bass (2002). Skala ini kemudian diperiksa oleh dosen pembimbing untuk melihat sejauh mana validitas isi dari skala yang dibuat.

\section{Teknik Pengumpulan Data}

Penelitian ini menggunakan skala Likert yang dimana skala likert digunakan untuk mengukur sikap, pendapat, dan presepsi seseorang atau kelompok tentang fenomena sosial. 
Dengan skala likert, maka variabel yang akan diukur, dijabarkan menjadi indikator variabel. Kemudian indikator atau aspek-aspek tersebut dijadikan tolak ukur untuk menyusun aitem-aitem instrumen berupa pertanyaan atau pernyataan (Sugiyono, 2010). Lalu setelah mendapatkan surat izin dari Fakultas Psikologi untuk melaksanakan penelitian di Kejaksaan Tinggi Sumatera Utara, lalu peneliti mempersiapkan 1 set eksemplar yang terdiri dari 2, yaitu skala quality of work life meliputi 50 butir aitem dan skala transformasional leadership yang berisi 40 butir aitem yang nantinya dibagikan kepada 105 partisipan.

Variabel dalam penelitian ini sebagai berikut: (1) Transformasional leadership adalah gaya kepemimpinan yang berorientasi pada hubungan emosional antar individu, sehingga setiap organisasi individu dalam menjadikan tujuan organisasi sebagai tujuan pribadi yang dapat mengerahkan seluruh potensi untuk mencapai tujuan organisasi. Skala Transformasional leadership dibuat berdasarkan aspek diantaranya: pemimpin teladan, motivasi yang menginspirasi, pertimbangan individual dan rangsangan berpikir. (2) Work life quality ialah kepuasan pegawai dalam memenuhi kebutuhan kerja dengan menambah pengalaman kerja dan mengacu kepada situasi lingkungan kerja yang nyaman dengan mendapatkan hasil kerja yang memuaskan dalam suatu organisasi. Quality of work life diungkap melalui skala yang disusun berdasarkan lima dimensi yaitu kepuasan kerja, kesehatan dan kesejahteraan, pengembangan kompetensi, keamanan kerja dankeseimbangan kehidupan kerja. Apabila skor yang diperoleh semakin tinggi maka semakin tinggi pula quality of work life sebaliknya jika skor yang diperoleh semakin rendah maka quality of work life juga semakin rendah.

\section{Teknik Analisis}

Pearson Product Moment sebagai teknik korelasi untuk menganalisis data hasil penelitian dibantu program komputer SPSS dengan mengunakan dua skala yaitu skala Quality of work life dan skala Transformasional leadership.

Teknik pengujian dengan uji validitas dan reabilitas. Validitas isi digunakan pada penelitian ini. Validitas isi mengarah pada sejauh mana isi sebuah instrumen/tes/skala mengukur apa yang semestinya diukur. Teknik Alpha Cronbach dipakai sebagai uji reliabilitas dibantu 
dengan program SPSS. Metode analisis data dilakukan sebelum data-data yang terkumpul dianalisa, mencakup: (1) Uji normalitas memakai teknik analisis Kolmogorov Smirnov dengan kriteria yang digunakan ialah data terdistribusi normal apabila $\mathrm{P}>0,05$ dan tidak terdistribusi normal jika $\mathrm{P}<0,05$ (Priyatno, 2010). (2) Uji linearitas hubungan antara kedua variabel yaitu apabila $\mathrm{P}<0,05$ maka transformasional leadership dengan quality of work life dikatakan linear, dan dikatakan tidak linear jika P > 0,05 (Priyatno, 2011).

\section{HASIL DAN PEMBAHASAN}

Berikut data deskriptif yang diperoleh dari setiap variabel:

Tabel 1.Hasil Analisis Deskriptif

\begin{tabular}{|c|c|c|c|c|c|c|c|c|}
\hline \multirow{2}{*}{ Variabel } & \multicolumn{3}{|c|}{ Empirik } & SD & \multicolumn{3}{c|}{ Hipotetik } & SD \\
\cline { 2 - 9 } & Min & Max & Mean & & Min & Max & Mean & \\
\hline $\begin{array}{c}\text { Quality of Work } \\
\text { Life }\end{array}$ & 60 & 132 & 99,66 & 13,312 & 50 & 200 & 125 & 25 \\
\hline $\begin{array}{c}\text { Transformationa } \\
\text { l leadership }\end{array}$ & 74 & 125 & 108,02 & 11,288 & 40 & 160 & 100 & 20 \\
\hline
\end{tabular}

Analisis dilakukan untuk menunjukkan apakah terdapat penyimpangan pada data yang diperoleh dari skala pengukuran.Deskriptif data pada penelitian ini mencakup skor empirik dan skor hipotetik.Selanjutnya subjek penelitian dikategorisasikan ke dalam 3 kategori. Adapun kategorisasi data Quality of Work Life pada tabel 2 berikut ini.

Tabel 2. Kategorisasi data Quality of work life dan Transformational leadership

\begin{tabular}{|c|c|c|c|c|}
\hline \multirow{2}{*}{ Variabel } & Rentang nilai & Kategori & Jumlah (n) & Persentase \\
\hline \multirow{3}{*}{ Quality of work life } & $\mathrm{x}<100$ & Rendah & 44 & 41,9 \\
\cline { 2 - 5 } & $100 \leq \mathrm{x}<150$ & Sedang & 61 & 58,1 \\
\cline { 2 - 5 } & $\mathrm{x} \geq 150$ & Tinggi & - & - \\
\hline \multirow{3}{*}{ Transformational leadership } & $\mathrm{x}<80$ & Rendah & 3 & 2,9 \\
\cline { 2 - 5 } & $80 \leq \mathrm{x}<120$ & Sedang & 90 & 85,7 \\
\cline { 2 - 5 } & $\mathrm{x} \geq 120$ & Tinggi & 12 & 11,4 \\
\hline
\end{tabular}


Melalui kategorisasi pada tabel 2, memperlihatkan bahwa pada variabel quality of work life terdapat 44 subjek (41,9 persen) dengan kategori rendah dan 61 subjek (58,1 persen) yang memiliki quality of work life sedang. Selanjutnya untuk variabel transformational leadership terdapat 3 subjek (2,9 persen) yang memiliki transformational leadership rendah, 90 subjek (85,7 persen) dengan kategori sedang, dan 12 subjek (11,4 persen) yang memiliki transformational leadership tinggi. Dengan penjelasan tersebut maka disimpulkan bahwa secara dominan subjek penelitian memiliki work life quality dan transformational leadership dengan kategori sedang.

Tabel 3. Hasil Uji Normalitas

\begin{tabular}{|c|c|c|c|c|c|}
\hline Variabel & SD & KS-Z & Sig. (1-tail) & P & Keterangan \\
\hline Quality of work life & 13,31196 & 1,018 & 0,125 & $\mathrm{P}>0,05$ & $\begin{array}{c}\text { Sebaran } \\
\text { normal }\end{array}$ \\
\hline $\begin{array}{c}\text { Transformational } \\
\text { leadeship }\end{array}$ & 11,22753 & 1,172 & 0,064 & $\mathrm{P}>0,05$ & $\begin{array}{c}\text { Sebaran } \\
\text { normal }\end{array}$ \\
\hline
\end{tabular}

Berdasarkan tabel 3, terlihat bahwa uji normalitas pada variabel quality of work life dan variabel transformational leadership terdistribusi normal.Selanjutnya dilakukan uji linearitas hubungan antara kedua variabel yang merupakan salah satu syarat dalam menganalisis korelasi data Pearson Product Moment.

Tabel 4.Hasil Uji Linearitas Hubungan

\begin{tabular}{|c|c|c|c|}
\hline Variabel & F & Sig & Keterangan \\
\hline Quality of work life & 57,388 & 0,000 & Linear \\
\hline
\end{tabular}

Pada tabel 4, menunjukkan variabel quality of work life dantransformational leadeship memperoleh korelasi yang linear. Hal ini terbukti melalui nilai signifikansi yang didapatkan yaitu 0,000 maka $\mathrm{p}<0,05$, dan dapat dilanjutkan dengan uji analisis korelasi Product Moment oleh Pearson.

Tabel 5. Uji Korelasi Transformational Leadeship dengan Quality of Work Life

\begin{tabular}{|c|c|c|}
\hline Analisis & Pearson Correlation & Signifikansi (p) \\
\hline Korelasi & 0,625 & 0,000 \\
\hline
\end{tabular}


Dari tabel 5, diperoleh hasil analisis korelasi sebesar 0,625 dengan sig 0,000 ( $\mathrm{p}<0,05)$ antara transformational leadeship dengan quality of work life.Yang menyatakan bahwa terdapat korelasi positif antara kedua variabel tersebut dan dikategorikan hubungan yang sedang (Sugiyono, 2010).Melalui hasil perhitungan itu, maka hipotesis penelitian ini diterima yakni ada hubungan antara transformational leadeship dengan kualitas hubungan kerja.

Tabel 6. Sumbangan Efektif

\begin{tabular}{|l|l|}
\hline Variabel & R Square \\
\hline $\begin{array}{l}\text { Transformational leadership } \\
\text { Quality of work life }\end{array}$ & 0,390 \\
\hline
\end{tabular}

Pada tabel 6, diperoleh koefisien determinasi $\left(\mathrm{R}^{2}\right)$ sebesar 0,390 dan dapat disimpulkan bahwa sumbangan 39 persen quality of work life mempengaruhi transformational leadeship dan selebihnya 61 persen disebabkan faktor lain, seperti kepuasan kerja, dan psychological wellbeing.

Menurut Northouse (2013) kepemimpinan merupakan proses pengembangan pemikiran dan cita-cita, menciptakan keputusan adil mengenai manusia dan sumber daya lainnya serta mendorong orang lain untuk merangkul pemimpin dalam perilakunya sendiri. Kepemimpinan juga merupakan proses seorang individu mampu memberi pengaruh terhadap sekelompok individu untuk mencapai tujuan bersama.

Seorang transformational leadership ialah pemimpin yang mengembangkan kompetensi bawahannya dengan leading by questions dan memberi tantangan agar pengikutnya mengasah pikiran untuk menciptakan cara baru dalam memenuhi tuntutan kerja, mengembangkan perspektif mereka dengan mengikut sertakan kehadirannya pada suatu hal yang memiliki banyak alternatif baru, meningkatkan suasana pembelajaran agar mereka nyaman dan antusias dalam memperlajari hal baru, memanfaatkan kesalahan sebagai sarana pembelajaran serta mengevaluasinya, dan menyiapkan fasilitas agar wawasan yang diterima terus berkembang (Ancok, 2012). Artinya transformational leadership ingin setiap pengikutnya dapat mengembangkan dirinya. Berdasarkan penjelasan ahli di atas dapat diketahui bahwa, seorang transformational leadership 
dapat membuat suasana kerja yang positif, membuat karyawan merasa dihargai, hingga dapat mendorong pengembangan kompetensi karyawan.

Selaras dengan penelitian Munandar (2017) yang menyatakan bahwa Transformational leadership memoderasi positif mempengaruhi work life quality karyawan dalam satu institusi, karena transformational leadership merupakan sebuah perilaku yang lebih dari sekedar mengambil inisiatif (proaktif), untuk meningkatkan perhatian atas kepentingan bersama terhadap para pegawai, pemimpin yang memodifikasi kepercayaan, nilai, dan tingkah laku para pengikut agar lebih konsisten dengan visi organisasi. Sifat-sifat kepemimpinan itu mampu meningkatkan kualitas kehidupan kerjakaryawan dalam organisasi tersebut.

Terdapat kekurangan dalam penelitian ini yaitu hanya melibatkan subjek pada satu kejaksaan di kota Medan, sehingga tidak dapat menjadi acuan apabila dilaksanakan di tempat ataupun wilayah lain karena hasil yang diperoleh bisa berbeda. Peneliti selanjutnya diharapkan mampu menelusuri faktor lain yang mempengaruhi work life quality dan dalam pembuatan aitem skala disarankan menggunakan kalimat jelas, singkat, sederhana, mudah dimengerti, dan tidak menimbulkan interpretasi ganda.

\section{KESIMPULAN}

Hasil penelitian ini menerangkan bahwa variabel transformational leadership memberikan sumbangan sebesar 39 persen terhadap quality of work life dan selebihnya 61 persen dikarenakan faktor lain, seperti job satisfaction, dan kesejahteraan psikologis. Demikian dapat disimpulkan bahwa terdapat hubungan positif antara quality of work life dengan transformational leadeship, yang berarti apabila transformational leadeship semakin tinggi, maka quality of work life yang dimiliki semakin tinggi.Sebaliknya apabila transformational leadeship semakin rendah maka quality of work life semakin rendah pula.

Saran peneliti bagi jaksa ialah agar lebih memperhatikan dan mengambil sisi positif terhadap lingkungan kerja karena hal tersebut dapat memengaruhi kepuasan dalam bekerja.Pemimpin organisasi atau kejaksaan juga disarankan untuk memotivasi dan memberi 
dukungan pada jaksa-jaksa agar mereka lebih terpacu sehingga diperoleh kepuasaan baik secara fisik maupun psikologis dan meningkatkan produktivitas organisasi.

\section{REFERENSI}

Ancok, D. (2012). Psikologi kepemimpinan dan inovasi. Erlangga.

Avolio, B. J., \& Bass, B. M. (Eds.). (2002). Developing Potential Across a Full Range of Leadership: Cases on Transactional and Transformational Leadership. Lawrence Erlbaum Associates.

Azalea, S., \& Himam, F. (2014). Kualitas Kehidupan Kerja Ditinjau Dari Komitmen Karir Dan Persepsi Gaya Kepemimpinan Transformasional. In Psikologika: Jurnal Pemikiran dan Penelitian Psikologi (Vol. 19, Issue 1). https://doi.org/10.20885/psikologika.vol19.iss1.art5

Bass, B. ., \& Riggio, R. E. (2006). Transformational Leadership (Second). Psychology Press.

Detik. (2014). PNS Pengadilan Mogok Kerja Minta Kenaikan Gaji, MA: Mereka Kurang Sabar. Detik.Com.

Djamali, R. A. (2014). Pengantar Hukum Indonesia. Raja Grafindo Persada.

Helmiatin. (2014). The Implementation of Transformational Leadership and Quality of Worklife toward Organizational Citizenship Behavior. International Journal of Innovation, Management and Technology, 5(5), 339-343. https://doi.org/10.7763/ijimt.2014.v5.537

Isaac, S., \& Michael, W. B. (1995). Handbook in research and evaluation: A collection of principles, methods, and strategies useful in the planning, design, and evaluation of studies in education and the behavioral sciences. Edits publishers.

Munandar, Y. A., \& Fuady, W. (2017). Pengaruh kualitas kehidupan kerja dan komitmen organisasional terhadap kinerja tenaga pendidik dengan kepemimpinan transformasional sebagai variabel moderasi. Jurnal Ekonomi Manajemen Akuntansi, 24(43).

Northouse, P. G. (2013). Kepemimpinan: Teori dan praktik. Indeks.

Undang-Undang Dasar 1945 No. 43 Tahun 1999 pasal 3 ayat 1 tentang Pokok-pokok Kepegawaian, Pub. L. No. Pasal 3 ayat 1 (1999).

Priyatno, D. (2011). Buku saku analisis statistik data SPSS. MediaKom.

Reddy, L. M., \& Reddy, M. P. (2010). Quality of work life of employees : emerging dimensions. Asian Journal of Management Research, 1(1), 827-839.

Sugiyono. (2010). Metode Penelitian Bisnis. Pendekatan Kuantitatif, kualitatif dan $R \&$ \& . Alfabeta.

Thoha, M. (2005). Manajemen kepegawaian sipil di Indonesia. Prenada Media. https://books.google.co.id/books?id=3niJtgAACAAJ 